\title{
Rancang Bangun Sistem Printer Tanpa Kabel Berbasis Bluetooth dan WIFI
}

\section{Communication System Design Wireless Printer Based on Bluetooth and WI-FI}

\author{
PUTRI DIAN PERTIWI \\ (0305202069) \\ PENDIDIKAN MATEMATIKA \\ FAKULTAS ILMU TARBIYAH DAN KEGURUAN \\ UNIVERSITAS SUMATRA UTARA
}

\begin{abstract}
Abstrak
Paper ini mempresentasikan perancangan sebuah sistem komunikasi printer tanpa kabel dengan menggunakan komunikasi bluetooth dan Wi-Fi. Sistem ini dirancang untuk menggantikan penggunaan kabel pada printer yang saat ini diakses melalui kabel, juga memanfaatkan fasilitas laptop/PC (Personal Computer) yang saat ini rata-rata sudah dilengkapi dengan fitur bluetooth dan Wi-Fi.
\end{abstract}

Kata kunci : Bluetooth, Wi-Fi

\section{Abstract}

This paper presented the design of a communication system printer wirelessly using Bluetooth communication and Wi-Fi. The system is designed to replace the use of cables to the printer that is currently accessed via a cable, also avail the facility of a laptop / PC (Personal Computer) is the current average is equipped with Bluetooth features and Wi-Fi. 
Keyword-Bluetooth, Wi-Fi

\section{PENDAHULUAN}

\section{A. Latar Belakang}

II. Printer adalah salah satu hardware (perangkat keras) yang terhubung ke komputer dan mempunyai fungsi untuk mencetak tulisan, gambar dan tampilan lainnya dari komputer ke media kertas atau sejenisnya. Perangkat elektronik ini menggunakan kabel sebagai media transmisinya.

III. Seiring berkembangnya zaman, sistem komunikasi nirkabel kini telah berkembang pada perangkat elektronika, komunikasi tersebut adalah Bluetooth dan Wi-Fi (Wireless Fidelity). Teknologi komunikasi nirkabel tersebut umumnya telah terpasang pada laptop dan PC (Personal Computer), ataupun Bluetooth sebagai perangkat tambahan yang harganya kini relatif murah. Dengan memanfaatkan teknologi tersebut pada printer, maka akan meminimalkan penggunaan kabel dan dalam melakukan pencetakan.

\section{A. Tujuan Penelitian}

Tujuan dari penelitian ini adalah sebagai berikut.

1. Untuk merancang sistem yang memiliki fitur Bluetooth dan Wi-Fi untuk komunikasi dari komputer ke printer.

2. Untuk memanfaatkan fasilitas yang ada pada laptop atau PC (Personal Computer) yang rata-rata sudah dilengkapi dengan fasilitas Bluetooth dan Wi-Fi.

\section{B. Batasan Masalah}

Dalam perancangan alat pada penelitian ini penulis membatasi beberapa batasan masalah sebagai berikut.

1. Perancangan sistem hanya pada perangkat untuk komunikasi Bluetooth dan Wi-Fi.

Jenis printer yang akan digunakan adalah printer standar dalam artian printer yang sebelumnya belum dilengkapi dengan fasilitas Bluetooth ataupun Wi-Fi. Contohnya printer merk Canon iP2770.

2. Koneksi hanya melalui PC (Personal Computer) atau laptop dan menggunakan Operating System Windows. 


\section{DASAR TEORI}

\section{A. Raspberry Pi}

Raspberry Pi (juga dikenal dengan RasPi) adalah sebuah SBC (Single Board Computer) yang menggunakan system on a chip (SoC) dari Broadcomm BCM2835, juga sudah termasuk prosesor ARM1176JZF-S 700 $\mathrm{MHz}$, GPU Video Core IV dan RAM sebesar 256 MB (untuk Rev. A) dan $512 \mathrm{MB}$ (untuk Rev. B).

Raspberry $\mathrm{Pi}$ menggunakan sistem operasi berbasis kernel Linux.Raspbian merupakan Sistem operasi berbasis Debian yang dapat bebas dioptimalkan untuk perangkat keras Raspberry Pi.

\section{B. Bluetooth}

Bluetooth adalah sebuah teknologi nirkabel dengan gelombang radio yang bekerja pada frekuensi $2.4 \mathrm{GHz}$. Bluetooth menggunakan sistem Frequency Hopping Spread Spectrum (FHSS) yang mempunyai kecepatan maksimum 1 Mbps.

Bluetooth memiliki lapisan-lapisan yang mempunyai fungsi berbeda sehingga secara umum digambarkan seperti Gambar 1 di bawah ini. 
1.

objek antar aplikasi yang berjalan dengan menggunakan Bluetooth.

3. Service Discovery Protocol (SDP) merupakan sebuah protokol yang berfungsi untuk memberikan layanan pencarian service terhadap Bluetooth device yang berada disekitarnya.

4. RFCOMM adalah protokol yang mempunyai fungsi untuk melakukan emulasi koneksi serial antar device Bluetooth.

5. Logical Link Control and Adaption Protocol (L2CAP) merupakan suatu lapisan dalam arsitektur Bluetooth yang dapat membuat paket-paket yang siap untuk digunakan oleh lapisan-lapisan yang berada di atasnya.

6. Human Computer Interface $(\mathrm{HCl})$ adalah layer antar muka antara perangkat keras Bluetooth dengan perangkat lunak atau platform.

7. Link Manager (LM) adalah protokol yang berfungsi untuk melakukan membangun kanal hubungan antara device Bluetooth setelah melakukan mekanisme sistem keamanan serta melakukan negosiasi berapa besar paket baseband yang akan dikirimkan.

8. Layer baseband mempunyai fungsi untuk melakukan sinkronisasi pengiriman data antar device Bluetooth.

Radio mempunyai fungsi untuk membuat gelombang radio yang mempunyai frekuensi $2.4 \mathrm{GHz}$ sesuai dengan data yang akan diterima maupun dikirimkan

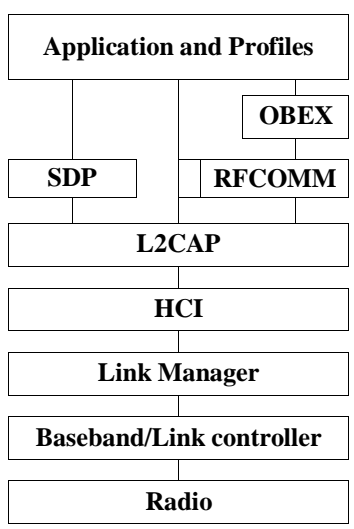


C.WIFI

Gambar 1. Arsitektur Bluetooth

Wi-Fi merupakan singkatan dari Wireless Fidelity, memiliki pengertian yaitu sekumpulan standar yang digunakan untuk Jaringan Lokal Nirkabel (Wireless Local Area Network, WLAN) yang didasari pada spesifikasi The Institute of Electrical and Electronics Engineer (IEEE)

802.11. Wi-Fi (atau WLAN) diciptakan terperinci untuk mengoperasikan sebagai ethernet tanpa kawat. Ini adalah satu teknologi open-standard yang memperbolehkan koneksi nirkabel di antara area alat-alat perlengkapan dan lokal jaringan. 
1. Profiles adalah aplikasi yang dibuat pada arsitektur Bluetooth.

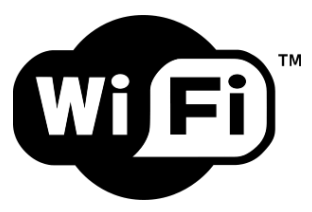

Object Exchange (OBEX) adalah protokol yang berfungsi untuk melakukan transfer Akses publik jasa WLAN didesain untuk menghubungkan dan melayani jaringan LAN dengan jarak radius 50 sampai 150 meter dari titik aksesdalam sebuah perusahaan, setiap departemen memiliki tugas yang berbeda, dan hanya terfokus padahal tertentu sesuai pembagian tugas. 


\section{Gambar 2. Logo Wi-Fi}

Wi-Fi dirancang berdasarkan spesifikasi IEEE

802.11. Sekarang ini ada empat variasi dari 802.11, yaitu: 802.11 a, 802.11b, 802.11g dan 802.11n. Spesifikasi $b$ merupakan produk pertama Wi-Fi.

\section{Protokol}

Protokol merupakan persetujuan antara dua entitas atau lebih tentang bagaimana entitas- etintas tersebut akan berkomunikasi satu dengan yang lainnya. Persetujuan -persetujuan yang dimaksud antara lain:

a. Bagaimana entitas-entitas akan memulai komunikasi atau mengakhiri komunikasi.

b. Proses sinkronisasi antara pengirim dan penerima.

c. Deteksi dan perbaikan kesalahan.

d. Format dan encoding data.

\section{OSI Layer}

Model referensi OSI terdiri dari 7 lapisan, mulai dari lapisan fisik hingga aplikasi. Model referensi ini tidak hanya berguna untuk produk- produk LAN saja, tetapi juga sangat diperlukan dalam membangun jaringan Internet.

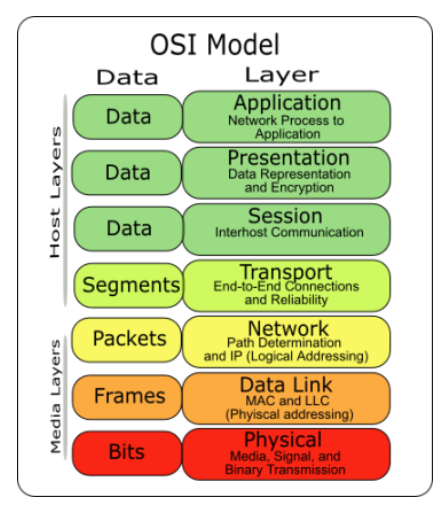

Gambar 3. OSI Layer

OSI menjelaskan bagaimana data dan informasi jaringan berkomunikasi dari sebuah aplikasi pada sebuah komputer berjalan melalui jaringan, menuju ke aplikasi di komputer lain. OSI menjelaskan melalui pendekatan pemecahan menjadi lapisan-lapisan (layer). Analogi konsep layer adalah seperti dalam departemen/bidang 


\section{E. TCP/IP}

TCP/IP (Transport Control Protocol/Internet Protocol) adalah sekumpulan protokol yang didesain untuk melakukan fungsi- fungsi komunikasi data pada Wide Area Network (WAN). TCP/IP terdiri dari sekumpulan protokol yang masing-masing bertanggung jawab atas bagianbagian tertentu dari komunikasi data. Berkat prinsip ini, tugas masingmasing protokol menjadi jelas dan sederhana.

Protokol yang satu tidak perlu mengetahui cara kerja protokol yang lain, sepanjang masih bisa saling mengirim dan menerima data. Berkat penggunaan prinsip ini, TCP/IP menjadi protokol komunikasi data yang fleksibel. TCP/IP dapat diterapkan dengan mudah di setiap jenis komputer dan interface jaringan, karena sebagian besar isi kumpulan protokol ini tidak spesifik terhadap satu komputer atau peralatan jaringan tertentu.

Alamat IP adalah alamat yang diberikan ke jaringan dan peralatan jaringan yang menggunakan protokol TCP/IP. Pembagian kelas- kelas alamat IP didasarkan pada dua hal yaitu network ID dan host ID. Setiap alamat IP merupakan sebuah pasangan dari network ID (identitas jaringan) dan host ID (identitas host dalam jaringan tersebut).

Tabel 1. Jenis IP Address

\begin{tabular}{|c|c|c|c|}
\hline $\begin{array}{c}\text { Kela } \\
\text { S }\end{array}$ & $\begin{array}{c}\text { Netw } \\
\text { Ork } \\
\text { ID }\end{array}$ & $\begin{array}{c}\text { Ho } \\
\text { st } \\
\text { ID }\end{array}$ & $\begin{array}{c}\text { Detault } \\
\text { Subnet } \\
\text { Mask }\end{array}$ \\
\hline A & W & X.y. & 255.0 .0 .0 \\
\hline B & W.x & y.z & 255.255 .0 \\
\hline C & Wx.y & L & $\begin{array}{c}\text { 255.255.2 } \\
55.0\end{array}$ \\
\hline
\end{tabular}

\section{v. PERANCANGAN ALAT}

\section{A. Perancangan Sistem}


gambaran umum (blok diagram) keseluruhan dari sistem komunikasi tanpa kabel pada printer. Dari blok diagram dijelaskan terdapat dua macam perangkat yang berfungsi untuk memberikan masukan untuk SBC (Single Board Computer). Sebelum terkoneksi dengan sistem, pengguna harus masuk ke jaringan Wi-Fi untuk koneksi Wi-Fi atau pairing dengan Bluetooth untuk memilih komunikasi menggunakan Bluetooth. Setelah terkoneksi, pengguna memilih printer yang telah disediakan sistem dan kemudian pengguna sudah dapat melakukan print out data yang akan dicetak. Input yang diterima berupa data-data dokumen, gambar dan yang sejenisnya

otomatis, namun pada saat print out data yang pertama yang akan dieksekusi terlebih dahulu sedangkan data yang kedua dan seterusnya akan disimpan dahulu sampai data yang pertama selesai di print out. Kemudian data selanjutnya yang akan dieksekusi dan seterusnya.

\section{PNGUJIAN DAN ANALISA}




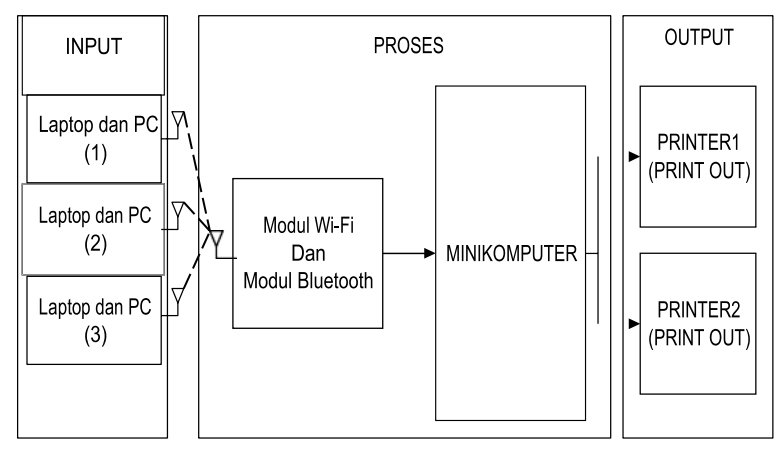

\section{A. Pengujian Konektivitas}

Pengujian dilakukan terhadap konektivitas

bluetooth dan Wi-Fi berdasarkan jarak. Pengujian konektivitas dilakukan untuk mengetahui jarak maksimal koneksi Wi-Fi dan bluetooth pada masing-masing yang sudah ditentukan.

\section{B. Perancangan Perangkat Lunak}

Perancangan perangkat lunak dibahas dengan menggunakan diagram alir (flowchart). Spesifikasi fungsional perangkat lunak yang dirancang harus dapat ditentukan melalui fungsi masukan (input) dan keluaran (output) program. Pada penelitian ini rancangan perangkat lunak dimulai dengan pembuatan sebuah flowchart seperti yang terlihat pada Gambar 5.

Pada awal diagram alir, SBC (Single Board Computer) membaca hardware yang terpasang, contohnya modul Bluetooth, modul Wi-Fi dan printer yang terpasang pada sistem. Setelah kondisi sistem siap SBC (Single Board Computer) secara otomatis akan menjadi printer server, modul Wi-Fi yang dijadikan akses poin oleh sistem akan standby untuk menerima client yang akan masuk pada jaringan yang disediakan oleh sistem printer nirkabel.

Pada rancang bangun sistem printer tanpa kabel ini, modul bluetooth juga dijadikan akses poin oleh sistem, walaupun dijadikan akses poin sistem hanya dapat menerima satu user saja dikarenakan komunikasi Bluetooth point to point.

Sistem menerima semua data yang dikirimkan melalui Bluetooth ataupun jaringan $\mathrm{Wi}-\mathrm{Fi}$, kemudian mengeksekusi data tersebut untuk di print out. Sistem akan menerima semua data yang masuk dan melakukan print out 
secaraTabel 2. Pengujian Konektivitas

\begin{tabular}{|c|c|c|c|c|c|}
\hline \multirow[t]{2}{*}{ Ke } & \multirow[t]{2}{*}{$\begin{array}{l}\text { Jar } \\
\text { ak } \\
\text { (m } \\
\text { ete } \\
\text { r) }\end{array}$} & \multicolumn{2}{|c|}{$\begin{array}{l}\text { Persen } \\
\text { tase } \\
\text { keberhasi } \\
\text { lan Wi-Fi }\end{array}$} & \multicolumn{2}{|c|}{$\begin{array}{l}\text { Perse } \\
\text { ntase } \\
\text { Keber } \\
\text { hasila } \\
n_{\text {Bluetoot }}\end{array}$} \\
\hline & & $\begin{array}{l}\text { Hala } \\
\text { ngan }\end{array}$ & $\begin{array}{l}\text { ran } \\
\text { pai } \\
\text { nala } \\
\text { ngan }\end{array}$ & $\begin{array}{l}\text { Hala } \\
\text { ngan }\end{array}$ & $\begin{array}{l}\text { ran } \\
\text { paa } \\
\text { nala } \\
\text { ngan }\end{array}$ \\
\hline 1 & 5 & $1 \% 0$ & $\begin{array}{c}10 \\
0 \%\end{array}$ & I\% & $\begin{array}{l}10 \\
0 \%\end{array}$ \\
\hline 2 & $\begin{array}{l}1 \\
0\end{array}$ & (ס & $\begin{array}{l}10 \\
0 \%\end{array}$ & U\% & $\begin{array}{l}10 \\
0 \%\end{array}$ \\
\hline 3 & $\begin{array}{l}2 \\
0\end{array}$ & I & $\begin{array}{l}10 \\
0 \%\end{array}$ & U\% & $0 \%$ \\
\hline 4 & $\begin{array}{l}4 \\
0\end{array}$ & U\% & $\begin{array}{l}10 \\
0 \%\end{array}$ & U\% & $0 \%$ \\
\hline 5 & $\begin{array}{l}5 \\
0\end{array}$ & U\% & $\begin{array}{l}10 \\
0 \%\end{array}$ & U\% & $0 \%$ \\
\hline
\end{tabular}

\section{B. Pengujian Print Out Berdasarkan Jarak dan Jenis File Melalui Komunikasi Wi-Fi}

Pengujian ini bertujuan untuk mengetahui persentase keberhasilan pada komunikasi Wi-Fi dan waktu yang dibutuhkan dalam melakukan eksekusi print out berdasarkan jarak, jenis file dan sistem operasi yang digunakan. Pengujian dilakukan dengan cara melakukan print pada jarak yang sudah ditentukan.

\section{Pengujian Print Out Secara Bersamaan Pada Satu Printer Melalui Komunikasi Wi-Fi}

Pengujian ini dilakukan untuk mengetahui urutan eksekusi print out, waktu yangjarak dan jenis file yang dikirimkan dengan halangan maupun tanpa halangan. diperlukan dan keberhasilan sistem untuk melakukan print out. Selain itu, pengujian dilakukan berdasarkan 


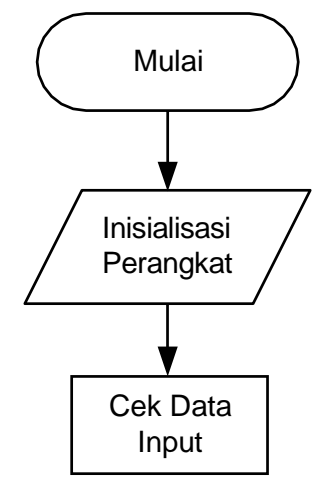

Koneksi wifi?

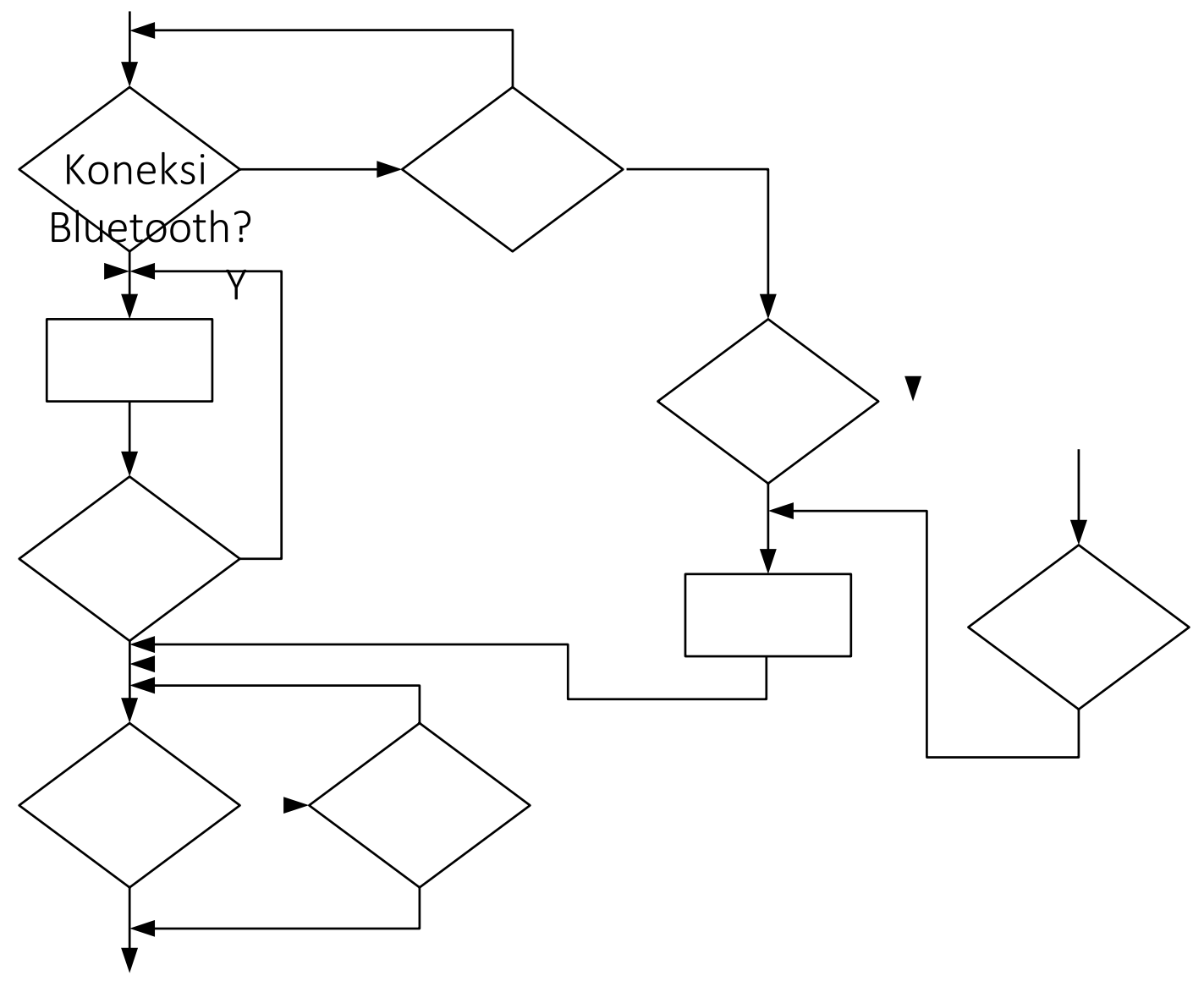


Koneksi Wi-Fi Ylain

Y

\begin{tabular}{lll} 
& Connecting \\
\hline
\end{tabular}

Connecting
Masukkan

Password

N

M

e

n

g

g

u

n

a

k

a

n

$P$

$r$

i

n

t

e

$r$

B

? 

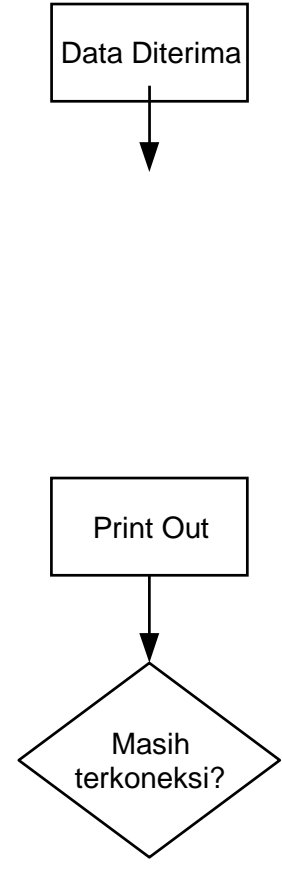

$\underline{Y}$

N

D. Gambar 5. Diagram Alir Sistem Rancang Bangun Komunikasi Tanpa Kabel Pada PrinterPengujian Print Out secara Bersamaan Pada Dua Printer Melalui Komunikasi Wi-Fi

Pengujian ini dilakukan ketika user/client yang menggunakan sistem operasi Windows yang berbeda melakukan print out secara bersamaan pada dua buah printer berbeda yang terpasang pada sistem. Pengujian ini dilakukan untuk mengetahui urutan eksekusi print out, waktu yang diperlukan dan keberhasilan sistem untuk melakukan print out.

E. Pengujian Print Out Berdasarkan Jarak dan Jenis File Melalui Komunukasi Bluetooth

Pengujian eksekusi print out berdasarkan jarak dan jenis file yang akan dikirimkan kepada sistem melalui komunikasi bluetooth. Pada 
pengujian menggunakan sistem operasi Windows yang berbeda. Pengujian dilakukan pada jarak 5 meter hingga 50 meter dengan halangan dan tanpa halangan. Selain itu pada setiap masing-masing jarak dilakukan pengiriman file dengan jenis file yang berbeda yaitu berupa teks, gambar dan file yang memiliki teks dan gambar.

\section{F. Pengujian Print Out Bersamaan Pada Satu Printer dengan Komunikasi Berbeda}

Pengujian eksekusi print out apabila user/client yang menggunakan sistem operasi Windows yang berbeda melakukan print out secara bersamaan pada satu buah printer menggunakan kedua komunikasi, yaitu melalui bluetooth dan Wi-Fi yang terpasang pada sistem. Pengujian ini dilakukan untuk mengetahui eksekusi print out, waktu yang diperlukan dan keberhasilan sistem untuk melakukan print out dengan menggunakan komunikasi yang berbeda.

\section{G. Pengujian Print Out Bersamaan Pada DuaPrinter Menggunakan Komunikasi Wi-Fi dan Bluetooth}

Pengujian eksekusi print out dilakukan ketika user/client yang menggunakan sistem operasi Windows yang berbeda dan juga menggunakan media komunikasi yang berbeda melakukan print out secara bersamaan pada dua buah printer yang berbeda melalui komunikasi bluetooth dan Wi-Fi yang terpasang pada sistem. Pengujian ini dilakukan untuk mengetahui keberhasilan eksekusi print out dan waktu yang diperlukan.

\section{PENUTUP}

\section{A. Kesimpuan}

Berdasarkan hasila analisis yang dilakukan di bab sebelumnya, maka dapat ditarik kesimpulan sebagai berikut.

1. Jarak kerja Wi-Fi sampai dengan 50 meter dengan kondisi tanpa 
halangan dan 40 meter dengan halangan. Sedangkan bluetooth saat kondisi hanya sampai 5 meter dan kondisi tanpa halangan hanya sampai pada jarak 10 meter.

2. Pada komunikasi Wi-Fi jumlah user lebih banyak karena komunikasinya point to multipoint, sedangkan bluetooth komunikasinya point to point sehingga yang dapat mengakses printer hanya satu user.

3. Media komunikasi bluetooth dan Wi-Fi dapat dijadikan media penghubung antara laptop/PC (Personal Computer) user dengan printer yang akan digunakan dengan cara menjadikan kedua media komunikasi tersebut sebagai akses poin. Printer yang terpasang padkomunikasi Wi-Fi dan bluetooth.

4. Kecepatan print out dipengaruhi oleh jarak dan besarnya kapasitas file/jenis file. Semakin jauh jarak maka waktu yang dibutuhkan akan semakin banyak sedangakn semakin dekat jaraknya maka akan lebih cepat sistem melakukan print out. Begitu juga dengan besar kapasitas file, semakin besar file nya maka akan membutuhkan waktu yang banyak dibandingkan dengan kapasitas file yang lebih kecil.

5. File yang dikirimkan melalui WI-Fi akan lebih cepat di print out oleh sistem dibandingkan dengan file yang dikrimkan melalui komunikasi bluetooth. Hal tersebut dikarenakan data rate Wi-Fi lebih besar dibandingkan dengan bluetooth yang memiliki data rate 2-3 Mbps.

a sistem akan di share oleh sistem sehingga user/client dapat mengakses printer tersebut melalui media

\section{B. Saran}

Berikut adalah saran-saran yang diharapkan dapat memberikan pengembangan terhadap sistem yang telah dirancang untuk saat ini.

1. Untuk pengembangan perangkat lebih dikembangkan dengan ditambahkan LCD untuk mengetahui status kondisi sistem dan perancangan perangkat lunak lebih dikembangkan agar tidak 
terjadi bug.

2. Pemilihan komponen lebih dikembangkan agar sistem bisa lebih cepat dalam pengeksekusian print out.

\section{DAFTAR PUSTAKA}

[5] Ladyada. (2014). Setting up a Raspberry Pi as a WIFI access point.http://learn.adafruit.com/setting-up-a-raspberry-pi-as-awifi-access-point.pdf, (8 Februari 2014)

[6] Santos, RA., \& Block, AE. (2012). Embedded Systems and Wireless Technology

[7] Hakim, MAI. (2013). Pemanfaatan Mini PC Raspberry Pi Sebagai Pengontrol Lampu Jarak Jauh Berbasis Web Pada Rumah. Skripsi. Teknik dan Ilmu Komputer/S1. Universitas Komputer Indonesia. Bandung

[8] Simanungkalit, S. (2013). Studi Komparasi Pengontrol Robot Mobil Pada Smartphone Android Berbasis Teknologi Nirkabel. Skripsi. Teknik dan Ilmu Komputer/S1. Universitas Komputer Indonesia. Bandung

[9] Membrey Peter., \& Hows David. -----. Learn Raspberry Pi with Linux. http://it-

ebookks.info/book/1970/learn_raspberry_pi_with_linux.pdf, (7

[10] Richardson Matt., Wllace Shawn. (2013). Getting Started with Raspberry Pi. http://it-ebooks.info/book/1354. (7 Februari 2014) [11] Wibowo, AS., Wardhani, KS. (2008). E-book Tutorial PERINTAH DASAR LINUX. ftp://167.205.50.45/pub/ISO- IMAGES/linux/filenyaputu-shinoda/PerintahDasarLinux.pdf. (8 Februari 2013) 